\title{
Publicar filosofía.
}

\author{
Fernando Infante del Rosal \\ Director de Thémata \\ Universidad de Sevilla, España
}

La pregunta por la filosofía, por qué sea la filosofía, encuentra en cada momento de su propia historia una respuesta diferente. Cuando Thémata nació, a mediados de los años ochenta del siglo pasado, la respuesta más general ponía a la filosofía en relación con el relevo, con la capacidad que el pensamiento tiene de darse como testigo, de ser objeto de un trasvase siempre actualizador y modificante. Era aquel, además, un tiempo de relecturas, de reapropiaciones, o mejor dicho, de generalización en la filosofía académica de las relecturas que ya habían hecho pensadores como Heidegger, Foucault o Vattimo (una secuencia de relevos que muestra tres hitos de la apropiación del pensamiento nietzscheano). Filosofía era entonces el pensamiento en su trasvase, disposición temporal abierta a la reconstrucción presente. La filosofía implicaba una responsabilidad hermenéutica y un necesario sinfronismo que no solamente permitían acceder a los textos y a las conciencias de otros tiempos, sino que buscaban, sobre todo, trasladarlos al ahora; y no para desvincularlos de su tiempo, sino para darles también uno nuevo. Filosofía era tiempo y herencia.

Una revista de filosofía se ofrecía en aquel momento como medio para ese juego de legados. Éramos entonces, además, más hegelianos, más modernistas, y asumíamos que el pensar necesitaba de sus propios desarrollos y de sus avatares temporales para darse como tal. Una revista que publicase filosofía se introducía en el ámbito académico como un modo de esa donación en el tiempo. Había que presentarse, dar a conocer las investigaciones, las ideas y las motivaciones de unos todavía jóvenes docentes y de algunos aun más jóvenes estudiantes; pero había que invocar también los pensamientos emblemáticos que marcaban el territorio del pensar. Entonces, se era auténticamente nietzscheano, wittgensteiniano, heideggeriano o zambraniano; no porque se tuviera a estos pensadores como objeto de estudio o porque se les aplicara algún tipo de idolatría, sino porque realmente se les reclamaba como mentes del presente, como voces aún activas. Se les 
requería, pero, sobre todo, se les precisaba.

Hoy, la investigación académica es otra cosa. La Academia es otra cosa. Y también la filosofía parece haberse convertido en otra cosa. No ya un hacer en el tiempo, no un favorecer la transposición o el relevo, sino más bien una textura, una urdimbre cerrada y densa hecha de incuantificables aportaciones, de innumerables voces que se solapan y tejen un espacio espeso e inconmensurable. El pensamiento que se entrevé en las publicaciones académicas es ahora trama, cantidad apretada que se sublima como cualidad solo desde una acumulación y una interrelación estadística propias de la era del Big Data.

La investigación en filosofía ha perdido parte de su responsabilidad respecto al tiempo y la herencia del pensar, se ha soltado de su propia secuencia, del encadenamiento suprapersonal del pensamiento filosófico, que necesita trascender la mente individual y darse en una serie intersubjetiva de hechos temporales.

Investigar y publicar en filosofía en la actualidad es adentrarse en esa malla sosteniéndose en la tirantez que produce un tejido tan denso y tan tenso. Más que el diálogo y la perspectiva, parece que nos mueve la voluntad de colocar pequeñas aportaciones dentro de una textura apelmazada y espesa, una de esas fotografías de grupo tan pobladas que se vacían de todo sentido que no sea la sola cantidad.

Es cierto que somos más cuidadosos y minuciosos a la hora de dibujar el estado actual de la cuestión en cualquier asunto, que tenemos más técnica; que desde las revistas académicas se favorecen más claramente las discusiones y réplicas, lo que hace que el conocimiento avance, aunque sea más por la generalización de problemas o emblemas que se tipifican como de interés en el momento presente, que porque se busque alcanzar evidencias o consensos. Es cierto que sabemos hacerlo mejor, que nos manejamos con normas del juego y criterios de valor académico que han definido el modo de hablar de quienes trabajamos en esto de la filosofía y la academia hasta un punto que no imaginábamos, pero todo eso ha contribuido en cierto modo a que el saber cómo haya arañado una parte significativa del saber.

No son excluyentes estas dos dimensiones - el saber y el saber cómo-, tampoco lo son la idea de filosofía como legado y la de filosofía como trama. Es posible que en el futuro estos modos se las vean con otros nuevos, y 
que las preocupaciones que mostramos hoy, como las que manifestábamos hace más de treinta años, revelen su ingenuidad, pero ahora nos toca lidiar con esta diatriba. Es difícil encontrar colegas que no vean los problemas de la nueva vida académica, con sus modos de medición, y que no lo declaren frecuentemente, pero todos coinciden en la responsabilidad de quienes tienen tras de sí una carrera más larga con quienes se han incorporado recientemente a la filosofía y a la investigación académica.

Las revistas de filosofía sabemos cómo actuar en aquello en que el conocimiento y el pensamiento se dejan establecer mediante métricas. Nuestros logros vienen marcados por ese reconocimiento cuantificable $y$, lo reconozcamos o no, esos resultados han llegado a hacerse más patentes y distinguidos que nuestras políticas editoriales. Nos debatimos entre las acciones dirigidas a dicho reconocimiento y los valores y motivaciones con los que nuestras publicaciones se fundaron, pero es posiblemente esta tensión entre la métrica y el valor lo que habría que mantener, aunque, como tensión, no tenga nada de feliz.

A cada disciplina, la primacía de la métrica le afectará de una manera distinta, y es evidente el desajuste producido entre las ciencias experimentales y sociales, por un lado, y las humanidades por otro; pero quizá lo sea aún más respecto a la filosofía, por lo que el pensar tiene de juego entre un momento íntimo e intransferible, entregado, sin embargo, a un ejercicio siempre intersubjetivo.

Esto no solo afectaría a la filosofía más especulativa, también a las tradiciones analíticas o empíricas, porque no es un asunto de niveles de abstracción en el enfoque o de generalidad en el contenido, sino de constitución de comunidades que vienen definidas, no ya por enfoques y contenidos, sino por métricas e índices. El asunto es ese: que la importante comunicabilidad y la necesaria intersubjetividad del pensar filosófico se vean determinadas por asuntos de medida editorial.

La citación, como modo de medida, es meramente formal, porque una cita puede implicar cosas tan distintas como la apropiación, la reelaboración, la influencia o el reconocimiento, y puede incluso darse por negación, para poner en cuestión o rechazar aquello que se cita (es sabido que existen autorías muy citadas por muy criticadas). Los diferentes índices Science Sitation Index, Social Science Citation Index y Ars \& Humanities Citation 
Index - se han visto sometidos a numerosos juicios y revisiones por razones diversas en las últimas décadas: hace más de cincuenta años, Margolis apuntaba ya que una cita podía estar motivada por razones diversas como la familiaridad, la lengua, la lealtad o algún interés propio.

Son muchos los inconvenientes señalados por los propios documentalistas: las revistas rechazan trabajos avanzados, que inauguren un campo sin labrar previamente o que aporten una idea excesivamente adelantada -para eso están los libros, se diría-; referentes importantes que no se citan porque se suponen obvios y se mantienen de forma implícita; la especialización de un asunto o un enfoque, que produce por eso menos citas, etc.

Todo esto se justifica porque la cantidad y la medida son los criterios más operativos para el análisis y la evaluación del conocimiento, y, a eso, poco podríamos objetar. Pero, ¿qué sucede cuando la manera de valorar afecta al modo original de hacer? ¿Qué ocurre cuando los modos de pensar, de plantear interrogantes, de establecer coordenadas, de buscar sentido, se ven imbuidos o determinados por esa tecnología del índice?

Evidentemente, toda crítica al sistema actual adolece de entrada de cierta nostalgia y atavismo románticos y no hay que permanecer ahí. Tan solo las revistas de filosofía podemos valorar, dentro de las limitaciones económicas y estructurales que nos caracterizan, en qué medida somos capaces de aplicar nuestras políticas editoriales como corrección o compensación de los males de la métrica para favorecer modos de relación y diálogo más auténticos.

El actual equipo editorial de Thémata. Revista de Filosofía tiene esto muy en cuenta, porque está directamente atado a quienes fundaron la publicación en 1983 y la sacaron a la luz un año después. Todas las acciones que hemos emprendido en los últimos años para reajustar los índices de la revista han estado motivadas principalmente por un hacer justicia a estas personas y al espíritu que las llevó a emprender un camino que ahora es provechoso para muchos. Si el reconocimiento viene dado en la actualidad por la medida, que esta no sirva solo para endurecer la compacta trama de la investigación presente, sino para mantener lo que de relevo y testigo hay en la tarea del pensar.

Sevilla, 1 de junio de 2021 